\title{
Correction to: Levoketoconazole improves clinical signs and symptoms and patient-reported outcomes in patients with Cushing's syndrome
}

\author{
Eliza B. Geer ${ }^{1}$ (D - Roberto Salvatori ${ }^{2} \cdot$ Atanaska Elenkova $^{3} \cdot$ Maria Fleseriu $^{4} \cdot$ Rosario Pivonello $^{5} \cdot$ Przemyslaw Witek $^{6}$. \\ Richard A. Feelders ${ }^{7} \cdot$ Marie Bex $^{8} \cdot$ Stina W. Borresen $^{9} \cdot$ Soraya Puglisi $^{10} \cdot$ Beverly M. K. Biller $^{11}$. Fredric Cohen ${ }^{12}$. \\ Francesca Pecori Giraldi ${ }^{13,14}$
}

Published online: 14 December 2020

(c) The Author(s) 2020

\section{Correction to: Pituitary https://doi.org/10.1007/s11102-020-01103-6}

The original version of the article unfortunately contained an error in the first name and the surname of one of the authors in the author group. The last author name was incorrectly published as 'F. Pecori Giraldi' and the corrected name is 'Francesca Pecori Giraldi' (First name: Francesca; Surname: Pecori Giraldi).

The original article has been corrected.

Open Access This article is licensed under a Creative Commons Attribution 4.0 International License, which permits use, sharing, adaptation, distribution and reproduction in any medium or format, as long as you give appropriate credit to the original author(s) and the source, provide a link to the Creative Commons licence, and indicate if changes were made. The images or other third party material in this article are included in the article's Creative Commons licence, unless indicated otherwise in a credit line to the material. If material is not included in the article's Creative Commons licence and your intended use is not permitted by statutory regulation or exceeds the permitted use, you will need to obtain permission directly from the copyright holder. To view a copy of this licence, visit http://creativecommons.org/licenses/by/4.0/.

Publisher's Note Springer Nature remains neutral with regard to jurisdictional claims in published maps and institutional affiliations.

8 University Hospitals Leuven, Leuven, Belgium

9 Department of Medical Endocrinology and Metabolism, Copenhagen University Hospital Rigshospitalet, Copenhagen, Denmark

10 Department of Clinical and Biological Sciences, San Luigi Gonzaga Hospital, University of Turin, Orbassano, Italy

11 Massachusetts General Hospital, Boston, MA, USA

12 Strongbridge Biopharma, Trevose, PA, USA

13 Department of Clinical Sciences \& Community Health, University of Milan, Milan, Italy

14 Neuroendocrinology Research Laboratory, Istituto Auxologico Italiano IRCCS, Milan, Italy 